\title{
Examining Pregnancy Related Socio-Cultural Factors Among Adolescent Girls in the Komenda-Edina-Eguafo-Abrem Municipality in the Central Region of Ghana: A Case-Control Study
}

\section{OPEN ACCESS}

Edited by:

William Edson Aaronson, Temple University, United States

Reviewed by:

Janet Marie Baiardi, University of Detroit Mercy,

United States

Iffat Elbarazi,

United Arab Emirates University,

United Arab Emirates

*Correspondence:

John Elvis Hagan Jr.

elvis.hagan@ucc.edu.gh

Specialty section:

This article was submitted to

Public Health Education and

Promotion,

a section of the journal

Frontiers in Public Health

Received: 18 December 2018 Accepted: 04 April 2019

Published: 24 April 2019

Citation:

Ahinkorah BO, Hagan JE Jr, Seidu A-A, Mintah JK, Sambah F, Schack T and Hormenu T (2019) Examining

Pregnancy Related Socio-Cultural

Factors Among Adolescent Girls in the

Komenda-Edina-Eguafo-Abrem

Municipality in the Central Region of

Ghana: A Case-Control Study.

Front. Public Health 7:93.

doi: 10.3389/fpubh.2019.00093

\author{
Bright Opoku Ahinkorah ${ }^{1}$, John Elvis Hagan Jr. ${ }^{2,3 *}$, Abdul-Aziz Seidu ${ }^{4}$, \\ Joseph Kwame Mintah ${ }^{1}$, Francis Sambah ${ }^{1}$, Thomas Schack ${ }^{3}$ and Thomas Hormenu ${ }^{5}$ \\ ${ }^{1}$ Australian Centre for Public and Population Health Research, University of Technology Sydney, Ultimo, NSW, Australia, \\ ${ }^{2}$ Department of Health, Physical Education, and Recreation, University of Cape Coast, Cape Coast, Ghana, ${ }^{3}$ Neurocognition \\ and Action-Biomechanics-Research Group, Faculty of Psychology and Sport Sciences, Bielefeld University, Bielefeld, \\ Germany, ${ }^{4}$ Department of Population and Health, University of Cape Coast, Cape Coast, Ghana, ${ }^{5}$ National Institutes of \\ Health, Section of Ethnicity and Health, DEOB, NIDDK, Bethesda, MD, United States
}

Background and Purpose: Given that Ghana continues to record higher rates of adolescent pregnancy among rural dwellers, notably, those living in the Brong Ahafo, Central and Volta regions, it is surprising that scholarly information related to socio-cultural determinants of this sequel in these mentioned areas of the country is limited. This study sought to examine the socio-cultural factors associated with pregnancy among adolescent girls in Komenda-Edina-Eguafo-Abrem (KEEA) Municipality in the Central Region of Ghana.

Methods and results: Using a matched case-control design with a 1:1 ratio, a facility-based sampling approach was used to select 400 adolescent females aged between 15 and 19 years. Chi-square analyses on the strictness level of rules and regulations in family $\left[\chi^{2}(1)=62.010, p<0.05\right]$, freedom within the family to discuss issues related to sexuality $\left[\chi^{2}{ }_{(1)}=9.600, p<0.05\right]$, religious support of sex before marriage $\left[\chi^{2}{ }_{(1)}=4.312, p<0.05\right]$, peer influence to engage in sexual intercourse $\left[\chi^{2}{ }_{(1)}\right.$ $=7.793, p<0.05]$, reaction of parents toward pregnancy $\left[\chi^{2}{ }_{(1)}=70.064, p<0.05\right]$, and reaction of siblings toward pregnancy $\left[\chi^{2}(1)=66.702, p<0.05\right]$ were significantly related to adolescents' pregnancy status. Additionally, binary logistic regression analysis also showed that non-pregnant adolescents were seven times more likely to belong to families with strict rules and regulations compared to pregnant adolescents [OR $=0.14$, $95 \% \mathrm{Cl}=(0.07-0.25), p \leq 0.01]$. Non-pregnant adolescents were 3 times more likely to have freedom within the family to discuss issues related to sexuality compared to pregnant adolescents [OR $=0.33,95 \% \mathrm{Cl}=(0.18-0.59), p \leq 0.01]$. However, pregnant adolescents were 3 times more likely to be influenced by their peers to engage in sexual intercourse $[\mathrm{OR}=2.63,95 \% \mathrm{Cl}=(1.46-4.74), p \leq 0.001]$ and 3 times more likely to have parents with positive reaction toward adolescent pregnancy compared to non-pregnant adolescents $[\mathrm{OR}=2.97,95 \% \mathrm{Cl}=(1.15-7.70), p \leq 0.05]$. Additionally, these pregnant 
adolescents were eight times more likely to have siblings with positive reaction toward adolescent pregnancy [OR $=7.74,95 \% \mathrm{Cl}=(2.59-21.4), p \leq 0.001$ ] compared to their non-pregnant counterparts.

Conclusion: Adolescent pregnancy heightens the risk of negating birth outcomes that is independent of recognized confounding variables. Therefore, adolescent girls in the KEEA Municipality are likely to experience continuous exposure to the risk of pregnancy with the existence of negative socio-cultural norms. Specific strategies need to involve multifaceted interventions that include education, competency-based skill training and support for young people, especially pregnant adolescents. Further research ought to determine which other factors would help us better understand circumstances that may lead to adolescent pregnancies in other areas of the region and perhaps among other subgroups.

Keywords: socio-cultural, pregnancy, adolescents, Central region, Ghana

\section{INTRODUCTION}

Adolescent pregnancy appears today as a complex tapestry where different dimensions interact. Adolescence is also defined by UNICEF (1), as a transition from childhood to adulthood often characterized by physical, psychological, and social changes. It is generally classified into two: early adolescence (10-14 years) and late adolescence (15-19 years). A major test at this stage of growth is that fresh feelings develop, friends assume greater importance, and interest builds in the opposite sex $(2,3)$. World Health Organization (4) defines adolescent pregnancy as pregnancy occurring in a girl aged 10-19 years. This pregnancy can occur among early adolescents (1014 years) and late adolescents (15-19 years). According to Erikson's theory of psychosocial development, adolescents from 12 onwards are saddled with a psychosocial crisis called identity vs. role confusion that may be experienced in adolescent pregnancy $(3,5)$.

Globally, about 16 million adolescents aged between 15 and 19 years give birth each year, accounting for $11 \%$ of all births worldwide $(6,7)$. Approximately $95 \%$ of adolescent pregnancies occur in low middle income countries (LMIC). Significant geographical variations exist; for instance, births to adolescents as a percentage of all births range from approximately $2 \%$ in China, to $18 \%$ in Latin America and the Caribbean, to more than $50 \%$ in Sub-Saharan Africa (8). Pregnancy cases among young mothers have become a significant burden, with statistics from LMICs suggesting that nearly $10 \%$ (i.e., 36.4 million) of girls become mothers by age 16. The highest proportions in the world were noted in Sub-Saharan Africa, South Central and Southeast Asia (8, 9). By 2013, Sub-Saharan Africa had the highest prevalence of adolescent pregnancy in the world in 2013 (9). Births to teenage mothers accounted for more than half of all the births in this region: an estimated 101 births per 1,000 women aged 15-19 (9). Most countries with teenage pregnancy levels more than $30 \%$ occur in sub-Saharan Africa (10), birth rates ranged from 150 or more to $<50$ births per 1,000 women of ages 15-19 in sub-Saharan Africa, with Central Africa experiencing the highest levels and Southern Africa having the lowest level (11).

The current situation of adolescent pregnancy in Ghana is not different from other developing societies. Adolescent pregnancy is endemic in Ghana. The Ghana Demographic and Health Survey 2014 report indicates that the rate of pregnancy among adolescents aged 15-19 was high, with rural dwellers and those living in the Brong Ahafo, Central and Volta regions recording the highest rates (12). This report reiterated that the number of adolescents who were pregnant with one child in the Central Region was 7\%. Within the Central Region, the Komenda-Edina-Eguafo-Abrem (KEEA) Municipality is one of the districts that have high prevalence of adolescent pregnancy. In 2016, out of the total pregnancies in the Municipality, $17.5 \%$ were adolescents (13). The past decade has seen no significant change in the rates reported between 2003 (14\%) and 2008 $(13 \%)(14,15)$. For example, about one in ten adolescents aged between 15 and 19 years had begun childbearing in urban areas in Ghana whilst about twice the number was the problem in the rural communities in 2009 (15). These trends show that Ghana continues to record higher rates of adolescent pregnancy.

Studies have identified sexual health knowledge, attitude, behavior, and health service accessibility, and acceptability as broad risk factors for pregnancy among adolescents (16, 17). Besides, other researchers have identified diverse sociocultural factors such as family structure, peer group influence, cultural permissiveness, family instability, early age of marriage, lack of knowledge of sexuality, lack of knowledge, and/or ineffective use of contraceptives to influence pregnancy among adolescents $(18,19)$. For example, East et al. (18) investigated the association between adolescent pregnancy and family history of teenage births. After controlling for socioeconomic and mothers' parenting characteristics, findings showed that adolescents whose mothers and sisters once had teenage births were at a higher risk of getting pregnant. Additionally, four maternal parenting measures (being single, lax parenting, approval of teenage sex and parenting, and low level of education) were significantly associated with study participants' increased risk of teenage 
pregnancy. Similarly, Osaikhuwuomwan and Osemwenkha (19) found in Nigeria that peer group pressure to have sex had the highest rating $(71.8 \%)$ on participants perceptions on the causes of adolescent pregnancy. Other items rated were ignorance on basics of sexuality and pregnancy $(60.1 \%)$ as well as reported poor uptake of contraception $(69.3 \%)$ by adolescents. Other studies found varied socio-cultural risk factors associated with high pregnancy rate among adolescents. The level of strictness of rules and regulations in the family, level of freedom within the family to discuss problems regarding love affairs; level of freedom within the family to discuss issues related to sexuality, parental attitudes toward sex, ineffective parenting, and poverty have been cited (20-22).

The negative health, psychosocial, and economic impact connected with adolescent pregnancy is worrisome and should not be underestimated. Adolescent pregnancy brings sudden change in the lives of young girls and in most cases negative consequences such as dropping out of school and interrupted education. Psychologically, these young girls experience higher levels of stress, despair, depression, feelings of helplessness, low self-esteem, a sense of personal failure, and suicide attempts than perhaps their older counterparts (19). Further, pregnant adolescents face increased stereotyping and stigma as young mothers. These negative behaviors can increase the risk of adolescent mothers' not accessing health services and becoming more socially isolated (23). Besides medical risks (e.g., dysfunctional labor, pregnancy-related infections, postpartum hemorrhage, premature rupture of membrane, and higher rates of premature and/or low birth weight babies), the economic implications for the adolescent mother and her child are of great consequence; poverty; unemployment and poor literacy among others $(19,24)$.

Therefore, an empirical enquiry on socio-cultural determinants associated with pregnancy in adolescent girls in one of the endemic areas (KEEA Municipality) of the Central Region of Ghana would be worthwhile. This research investigation would provide some baseline information to strengthen the knowledge base and help policy makers set innovative community-wide approaches to reduce adolescent pregnancies through evidence-based prevention programs within this geographical area.

\section{MATERIALS AND METHODS Study Design}

A matched case-control study design with a 1:1 ratio was used for the study. A case was defined as any female adolescent (aged 15-19 years) who was pregnant and accessed healthcare in any of the health facilities in the KEEA Municipality in this study. Controls were defined as girls within adolescence (at the time of data collection) who have never been pregnant. We justify the use of this design because it enables researchers to identify risk factors associated with health behaviors such as adolescent pregnancy by explicitly focusing on cases (adolescent group known to have a pregnancy outcome) and the controls (adolescent group known to be free of pregnancy outcome). Then, we look back in time to learn which subjects in each group had the exposure comparable to studied variables. Ethical approval for this study was sought from the Research and Ethics Committee of University of Cape Coast, Ghana (UCCIRB/CES/2016/04) and the Ghana Health Service Ethics Review Committee (GHSERC: $13 / 12 / 2016)$. Permission to carry out the study was also obtained from the Central Regional Health Directorate, the KEEA Municipality Health Directorate and the health facilities involved in the study.

\section{Study Setting}

The study setting was the KEEA Municipality. According to the 2010 Population and Housing Census, the population of KEEA Municipality was 144,705 . The population represented $6.6 \%$ of the region's total population. Males constitute $48.2 \%$ whereas females represent $51.8 \%$. Sixty four percent $(64 \%)$ of the population is rural. The population of the district is youthful because $40.2 \%$ of the population is below 15 years, depicting a broad base population pyramid which tapers off with a small number of elderly persons (8.6\%). This Municipality has a General Fertility Rate of 105.0 births per 1,000 females aged 1549 years and a Total Fertility Rate of 3.6. The Crude Birth Rate (CBR) of the Municipality is 24.6 per 1,000 population (25).

\section{Population and Sampling}

The population for the study was made up of female adolescents (15-19) years in the KEEA Municipality. A total population of 7,667 females (10-19 years), comprising both pregnant and nonpregnant adolescents was used for the study (25). A facility based sampling approach was used to select 400 female adolescents made up of 200 pregnant and 200 non-pregnant adolescents. This sample size was determined using Krejcie and Morgan (26) table of determining sample sizes. With this sampling approach, pregnant adolescents accessing antenatal services from five health facilities in the municipality were initially purposively and conveniently selected. The health facilities were Kissi health center, Komenda health center, Elmina urban health center, Agona health center and Ankaful General Hospital. For each pregnant adolescent selected, a non-pregnant adolescent within the same age group was conveniently identified from the five health facilities. The number of pregnant adolescents and non-pregnant adolescents sampled constituted the number of cases and controls for the study. The choice of the facilitybased sampling was because it was difficult to reach potential participants using other sampling techniques.

\section{Instrumentation}

A literature review was the source from which questionnaire items were generated. The questionnaire consisted of preliminary information on participants' demographics (e.g., religion, mother and father's educational status, employment status). Other items on the instrument were socio-cultural factors related to pregnancy within which respondents were to answer with a binary response (e.g., Yes or No). Some specific examples of items on the instrument were "Freedom within the family to discuss issues related to sexuality; Religious support of sex before marriage." Face, construct and content validity were ensured by presenting the pre-test version of the questionnaire 
to three experienced professors in adolescent health education and promotion for their review and input to ensure that the individual item construction and whole content of the questionnaire mirrored the exact rational of the study (27). The questionnaire was then pre-tested using 50 adolescents in the Cape Coast Metropolis. Using the Kuder-Richardson formula 21 (KR-21), the instrument yielded a reliability coefficient of 0.71 , a figure that is deemed acceptable (28).

\section{Procedure}

An initial arrangement was made with the medical directors of the five (5) designated health centers to collect data from potential females. Two of the researchers and two trained assistants visited these health posts and collected data consistently for 12 weeks. The time period for the data collection was staggered with the senior nurses of the centers to avoid disruptions in their normal health delivery services. On each day of data collection, the rational of the study was clearly explained to participants. For each pregnant adolescent identified, a non-pregnant counterpart was available for the completion of the instrument at each center during the whole period. The completion of the instrument was done simultaneously in the conference rooms of these chosen health facilities. Standard instructions were read to all participants who agreed to provide information on the questionnaire. The trained research assistants and volunteered nurses helped with the administration of the questionnaire to some respondents, especially to those who needed assistance with the interpretation of some information in our local dialect due to their inadequate proficiency in English language. The data collection process commenced after briefing and inform consent agreement reached with the study participants and assurance that information obtained was solely for academic purpose. Participation was entirely voluntary and participants were asked to withdraw from the study at any time they felt uncomfortable. Other considerations such as anonymity, respect, and confidentiality were persevered at all stages of the data collection process by omitting any personal identifier from the questionnaire.

\section{Data Analysis}

Each completed questionnaire was coded on pre-arranged coding sheet by the researchers to minimize errors. Data were cleaned and entered into SPSS version 21 for analysis. Bivariate analysis using chi-square test of independence was initially performed between the dependent variable (pregnancy status) and each of the independent variables (socio-cultural factors) to identify the independent variables that showed statistically significant association with the dependent variable. The independent variables that showed statistically significant association with the dependent variable were further put in a multiple regression model to determine their influence on the dependent variable. Odds ratio (OR) at $95 \%$ confidence intervals (CI) and $p$ values were obtained for significant variables in the bivariate analysis. All variables found to be significant at the bivariate level $(p \leq 0.05)$ were entered into a multivariate analysis model in order to control for the effect of confounding variables. For easy interpretation, all odds ratios $<1$ were reversed to get whole numbers and interpretations were done based on the reverse values.

\section{RESULTS}

\section{Socio-Demographic Characteristics of Respondents}

The results of Table 1 show that with religion, majority of the pregnant and non-pregnant adolescents were Christians (95 and 94.5\%), respectively. For educational level, most of the pregnant and non-pregnant adolescents had more than primary education (64 and 52\%), respectively. With mothers' level of education, 61.2 and $85.7 \%$ of the pregnant and non-pregnant adolescents' mothers had more than primary education. In relation to the fathers' level of education, majority of pregnant adolescents fathers (70.1\%) and the non-pregnant adolescents' fathers $(89.3 \%)$ had more than primary education. Most of the pregnant and non-pregnant adolescents' mothers (77.5 and $88.4 \%$ ) were employed. Similar results, $77.5 \%$ of the pregnant adolescents' fathers and $89.8 \%$ of non-pregnant adolescents' fathers were employed.

\section{Socio-Cultural Factors Associated With Adolescent Pregnancy}

Table 2 shows the results of a bivariate analysis of the sociocultural factors that influence pregnancy among adolescents in the KEEA Municipality. In the bivariate analysis, all the independent variables had statistically significant association with adolescent pregnancy. In relation to the level of strictness of rules and regulations in family, the highest proportion of pregnancy $(79.2 \%)$ was recorded among adolescent girls whose families had no strict rules and regulations. Again, 56\% of adolescent girls who do not have the freedom within the family to discuss issues related to sexuality were pregnant. Adolescent girls whose religions support sex before marriage recorded the highest proportion of pregnancy (64.7\%). Above average (61.3\%) of adolescent girls indicated that their peers influence them to engage in sexual intercourse, those whose parents would be happy if they got pregnant $(86.7 \%)$ and those whose siblings will be happy if they got pregnant $(87.1 \%)$ were those who were pregnant. From the chi-square analysis, level of strictness of rules and regulations in family $\left[\chi^{2}(1)=62.010, p<0.05\right]$, freedom within the family to discuss issues related to sexuality $\left[\chi^{2}(1)\right.$ $=9.600, p<0.05]$, religious support of sex before marriage $\left[\chi^{2}{ }_{(1)}==4.312, p<0.05\right]$, peer influence to engage in sexual intercourse $\left[\chi^{2}{ }_{(1)}=7.793, p<0.05\right]$, reaction of parents toward pregnancy $\left[\chi^{2}(1)=70.064, p<0.05\right]$, and reaction of siblings toward pregnancy $\left[\chi^{2}(1)=66.702, p<0.05\right]$ showed statistically significant relationship with pregnancy status.

In the multivariate analysis, five independent variables (level of strictness of rules and regulations in family, freedom within the family to discuss issues related to sexuality, peer influence to engage in sexual intercourse, attitude of parents toward pregnancy, and attitude of siblings toward pregnancy) showed statistically significant influence on adolescent pregnancy. 
TABLE 1 | Socio-demographic characteristics of respondents.

\begin{tabular}{|c|c|c|c|c|}
\hline \multirow[t]{2}{*}{ Socio-demographic factors } & \multicolumn{2}{|c|}{ Pregnant $(n=200)$} & \multicolumn{2}{|c|}{ Non-pregnant $(n=200)$} \\
\hline & $N$ & $\%$ & $N$ & $\%$ \\
\hline \multicolumn{5}{|l|}{ RELIGION } \\
\hline Non-Christians & 10 & 5 & 11 & 5.5 \\
\hline Christians & 190 & 95 & 189 & 94.5 \\
\hline \multicolumn{5}{|l|}{ EDUCATIONAL LEVEL } \\
\hline Primary education or less & 5 & 2.5 & 2 & 1 \\
\hline >primary education & 195 & 97.5 & 198 & 99 \\
\hline \multicolumn{5}{|c|}{ MOTHER'S LEVEL OF EDUCATION } \\
\hline Primary education or less & 59 & 38.8 & 24 & 14.3 \\
\hline >primary education & 93 & 61.2 & 144 & 85.7 \\
\hline \multicolumn{5}{|c|}{ FATHER'S LEVEL OF EDUCATION } \\
\hline Primary education or less & 40 & 29.9 & 16 & 10.7 \\
\hline >primary education & 94 & 70.1 & 133 & 89.3 \\
\hline \multicolumn{5}{|c|}{ MOTHER'S EMPLOYMENT STATUS } \\
\hline Unemployed & 43 & 22.5 & 23 & 11.6 \\
\hline Employed & 148 & 77.5 & 176 & 88.4 \\
\hline \multicolumn{5}{|c|}{ FATHER'S EMPLOYMENT STATUS } \\
\hline Unemployed & 42 & 24.3 & 20 & 10.2 \\
\hline Employed & 131 & 75.7 & 177 & 89.8 \\
\hline
\end{tabular}

The full model containing all the predictors was statistically significant $\left[\chi^{2}(6)=156.5, p<0.05\right]$, indicating that the model was able to distinguish between respondents who were pregnant and those who were not pregnant. The model as a whole explained between 35\% (Cox \& Snell $R^{2}$ ) and 47\% (Nagelkerke $R^{2}$ ) of variance in pregnancy status (see Table 3 ). Comparison of the socio-cultural factors associated with pregnancy among the respondents shows that non-pregnant adolescents were 7 times more likely to belong to families with strict rules and regulations compared to pregnant adolescents $[\mathrm{OR}=0.14,95 \% \mathrm{CI}=[0.07-$ 0.25 ], $p \leq 0.01$ ]. Additionally, non-pregnant adolescents were 3 times more likely to have freedom within the family to discuss issues related to sexuality compared to pregnant adolescents $[\mathrm{OR}=0.33,95 \% \mathrm{CI}=[0.18-0.59], \mathrm{p} \leq 0.01]$. Again, pregnant adolescents were 3 times more likely to be influenced by peers to engage in sexual intercourse $[\mathrm{OR}=2.63,95 \% \mathrm{CI}=[1.46-4.74]$, $p \leq 0.001$. Similarly, pregnant adolescents were 3 times more likely to have parents with positive reaction toward adolescent pregnancy compared to non-pregnant adolescents $[\mathrm{OR}=2.97$, $95 \% \mathrm{CI}=[1.15-7.70], p \leq 0.05]$. Further, pregnant adolescents were 8 times more likely to have siblings with positive reaction toward adolescent pregnancy $[\mathrm{OR}=7.74,95 \% \mathrm{CI}=[2.59-21.4]$, $p \leq 0.001]$ compared with non-pregnant counterparts.

\section{DISCUSSION}

This study sought to identify and examine what socio-cultural factors influence pregnancy among selected adolescent girls in one of the endemic areas (KEEA Municipality) of the Central Region of Ghana. Findings show that non-pregnant adolescents are more likely to belong to families with strict rules and regulations. We do infer that adolescents whose parents or guardians have well-laid down monitoring and supervision guide (i.e., through rules and regulations) for their children may reduce adolescents' pregnancy risk such that these girls may refrain from sexual engagement (abstinence), postpone sexual intercourse (i.e., later sexual debut) and/ or have no sexual partners $(29,30)$. This finding corroborates other studies [e.g., (18, 20, 31-33)] that reported inverse relationship between parental monitoring (i.e., strict rules and regulations) and adolescent pregnancy risk (i.e., adolescents not having sexual intercourse or having sex less often. However, few studies have reported contradictory findings by failing to show the association between parental strict control and adolescent pregnancy risk. For example, Resnick et al. (34) reported that parents' presence at home before and after school, at dinner, and at bedtime (as regulatory mechanism) was not related to adolescents' pregnancy history. Likewise, mothers' strictness and rules were not related to daughters' sexual intercourse status, after other variables were controlled (35). A plausible reason for these mixed findings is that parental control is connected with negative adolescent behavior, including sex if it is excessive or coercive (29). Evidence supports the linkage between adolescent pregnancy risk with parents' intrusive psychological control. For instance, Miller et al. (33) found that adolescents who perceived their parents to be "very strict" with "many rules" were more likely to have had sexual intercourse than their peers who perceived their parents to be more flexible or exhibit moderate parental control. More research is thus required for additional conceptual and empirical clarification.

Consistent with previous studies [e.g., $(30,35,36)]$, the freedom within the family to discuss issues related to sexuality was related to adolescent pregnancy in this study. Specifically, 
TABLE 2 | Bivariate analysis of socio-cultural factors associated with adolescent pregnancy.

\begin{tabular}{|c|c|c|c|c|}
\hline Socio-cultural factors & Pregnant \% & Non-pregnant \% & Chi-square $\left(\chi^{2}\right)$ & $P$-Value $(95 \% \mathrm{Cl})$ \\
\hline \multicolumn{3}{|c|}{ Level of strictness of rules and regulations in family } & 62.010 & $0.000^{*}$ \\
\hline Not strict & 79.2 & 20.8 & & \\
\hline Strict & 36.7 & 63.3 & & \\
\hline \multicolumn{3}{|c|}{ Freedom within the family to discuss issues related to sexuality } & 9.600 & $0.002^{*}$ \\
\hline No & 56 & 44 & & \\
\hline Yes & 40 & 60 & & \\
\hline \multicolumn{3}{|c|}{ Religious support of sex before marriage } & 4.312 & $0.038^{*}$ \\
\hline No & 46 & 54 & & \\
\hline Yes & 64.7 & 35.3 & & \\
\hline \multicolumn{3}{|c|}{ Peer influence to engage in sexual intercourse } & 7.793 & $0.005^{\star}$ \\
\hline No & 45.7 & 54.3 & & \\
\hline Yes & 61.3 & 38.7 & & \\
\hline \multicolumn{3}{|c|}{ Reaction of parents toward pregnancy } & 70.064 & $0.000^{*}$ \\
\hline Sad & 38.1 & 61.9 & & \\
\hline Happy & 86.7 & 13.3 & & \\
\hline \multicolumn{3}{|c|}{ Reaction of siblings toward pregnancy } & 66.702 & $0.000^{*}$ \\
\hline Sad & 38.8 & 61.2 & & \\
\hline Happy & 87.1 & 12.9 & & \\
\hline
\end{tabular}

*Significant results

non-pregnant adolescents were more likely than pregnant adolescents to have the freedom within the family to discuss issues related to sexuality. There is enough evidence to suggest that an open, positive, and frequent parent/child communication about sexuality is connected with adolescents not having sexual intercourse, postponing their sexual debut, and/ or having fewer sexual partners will reduced risk of pregnancy. Comparatively, there are some studies that have reported conflicting findings; that is, the amount or frequency of parent/child sexual communication being associated with sons $(37,38)$ or daughters (39) or both (40) being more likely to have sexual intercourse, thus increasing pregnancy risk among adolescents. Methodological limitations (e.g., different measures [i.e., ever talked about sex (communication content), regularity of sexual communication, number of topics discussed as well as temporal ordering]) have been cited as potential reasons accounting for the complexity surrounding parent/child communication and adolescent pregnancy risk inconclusive findings $(29,30,41)$. Future research should consider the potential interactive effects between these aforementioned measures toward the prediction of adolescents' pregnancy risk using longitudinal designs compared to cross-sectional studies that currently dominate literature.

Our current study also demonstrated that peer pressure to engage in sexual intercourse was found to be a risk factor for adolescent pregnancy. Previous studies have likewise recounted that peer influence can support in the promotion or prevention of adolescent pregnancy through multiple pathways (e.g., attitudes and behaviors; perceptions) and that perceptions of their peers' attitudes and behaviors were found to be more influential toward increased pregnancy risk $(22,42-44)$. Hayes suggested that if an adolescent has confidence in his or her peers as sexually active although they might not be, this belief will increase the adolescent's prospect of engaging in sexual intercourse. This premise is consistent with our finding where adolescent pregnancy was ascribed to peer influence to engage in sexual intercourse by $61 \%$ of our study participants. Similarly, having a boyfriend, especially if adolescent girls are dating an older male counterpart has been associated with an increased risk of adolescent pregnancy (43).

Positive attitude of parents and siblings toward pregnancy was also found to be a risk factor for adolescent pregnancy. Some researchers have argued cogently that parents' sexual attitudes and values determine whether these young girls would have sexual intercourse, the onset of their sexual debut, the number of sexual partners encountered, their use of contraceptives, and whether they have ever been pregnant [e.g., (18, 22, 4548)]. For instance, Dittuset et al. (49) highlighted that sexual intercourse was deferred among Black adolescents when their fathers were perceived as condemning any sort of sexual engagement. Reasonably, parents' positive attitudes and values for their adolescent children to avoid pregnancy (i.e., sexual abstinence) are efficiently transferred when parents have a close bond (i.e., connectedness) with their children $(48,50)$. Similarly, the extent to which younger siblings exhibit risky sexual behaviors, manifest strongly if older siblings have had sexual intercourse and have experienced an adolescent pregnancy or birth in their family history (31, 51-53). Again, sibling modeling effects on adolescents' sexual attitudes and sexual behavior are most prevalent when siblings interact frequently and have a warm and amiable relationship (18). It is therefore interesting to find that pregnant adolescents are more likely to have siblings who support adolescent pregnancy compared to non-pregnant adolescents. Thus, within a family where parents 
TABLE 3 | Multivariate analysis of socio-cultural factors associated with adolescent pregnancy.

\begin{tabular}{|c|c|c|c|c|c|c|}
\hline & Pregnant \% & Non-pregnant \% & B & Wald & OR (Cl) & $p$-value \\
\hline Pseudo $R^{2}$ & $0.35-0.47$ & & & & & \\
\hline$x^{2}$ & 156.5 & & & & & \\
\hline$p$-value & 0.000 & & & & & \\
\hline \multicolumn{7}{|c|}{ LEVEL OF STRICTNESS OF RULES AND REGULATIONS IN FAMILY } \\
\hline Not strict & 79.2 & 20.8 & -1.991 & 41.407 & Ref & \\
\hline No & 56 & 44 & -1.120 & 13.850 & Ref & \\
\hline Yes & 40 & 60 & & & $0.33(0.18-0.59)$ & $0.000^{*}$ \\
\hline \multicolumn{7}{|c|}{ RELIGIOUS SUPPORT OF SEX BEFORE MARRIAGE } \\
\hline No & 46 & 54 & 0.719 & 2.551 & Ref & \\
\hline Yes & 64.7 & 35.3 & & & $2.05(0.85-4.96)$ & 0.110 \\
\hline \multicolumn{7}{|c|}{ REACTION OF PARENTS TOWARD PREGNANCY } \\
\hline Sad & 38.1 & 61.9 & 1.089 & 5.019 & Ref & \\
\hline Happy & 86.7 & 13.3 & & & $2.97(1.15-7.70)$ & $0.025^{*}$ \\
\hline \multicolumn{7}{|c|}{ REACTION OF SIBLINGS TOWARD PREGNANCY } \\
\hline Sad & 38.8 & 61.2 & 2.007 & 13.875 & Ref & \\
\hline Happy & 87.1 & 12.9 & & & $7.44(2.59-21.4)$ & $0.000^{*}$ \\
\hline
\end{tabular}

"Significant results

and siblings are happy when an adolescent girl gets pregnant, may influence the sexual behavior of adolescents in the family.

\section{LIMITATIONS}

This study may be subject to some limitations. The study was restricted to five health facilities in the KEEA Municipality of the Central Region of Ghana. Therefore, the findings cannot be generalized to other parts or areas of this Municipality or the country. By using a case-control design, temporal relationship between cause and effect cannot be determined from the outcomes (54). Additionally, this approach may be beset with both sampling errors and recall bias (55). Further, by assessing predictor variables retrospectively, there is the likelihood of a biased assessment of their presence and significance by participants or the investigator or both. These challenges were addressed by sampling cases and controls that have similar characteristics aside pregnancy status. Again, respondents were given adequate time to recall various events that had occurred in the past.

\section{Practical Implications}

Some of the contextual indicators (e.g., parental supervision [i.e., adopting strict rules and regulations]), parental communication, peer influence, parental and siblings' attitudes do make a difference toward risk of adolescent pregnancy. However, there are other multifaceted variables (e.g., family and neighborhood connectedness) that increase pregnancy risk, other adolescent sexual and reproductive health concerns seem to be complicated and inconclusive (56). For example, diverse family, societal, cultural, and religious influences create unfriendly environment for the discussion of adolescent sexuality related issues. Many societies (e.g., Ghana) across the Sub-Saharan region hold an entrenched position of disapproval toward adolescent sexual activity. This is often shown through stigmatization and stereotypical behaviors which increase the risk of adolescent mothers not accessing health and other social services in the communities, thus become more socially isolated and rejected. Based on our findings, we believe that reducing adolescent pregnancy rates warrant comprehensive multifaceted strategies. Attention should be drawn to the Municipal Assembly, educational and health directorates within KEEA toward improving sex education and access to sexual and reproductive health services. Attempts should also target addressing economic inequalities, improving education and employment opportunities for the large adolescent population in KEEA Municipality and perhaps other deprived areas in the country. Programs such as specific competency-based skill based education and training should be implemented. Such programs should include academic and social skills, particularly those that would include adolescents' parents, family and the broader community.

\section{CONCLUSION}

Findings from the study show that adolescent girls in the KEEA Municipality are likely to be exposed to the risk 
of pregnancy with the existence of negative socio-cultural norms. Most of the pregnant adolescents had no freedom within the family to discuss issues related to sexuality, were influenced by peer influence to engage in sexual intercourse and had parents and siblings with positive attitudes toward adolescent pregnancy compared to non-pregnant adolescents. Specific strategies need to involve multifaceted interventions that include education, competency-based skill training and support for young people, especially pregnant adolescents. Additionally, existing ethics and positive cultural values at the community level should be enforced. Further research is required to determine which other factors would help us better understand circumstances that may lead to adolescent pregnancies in other areas of the region and perhaps among other subgroups.

\section{ETHICS STATEMENT}

Ethical approval for this study was approved by the Research and Ethics Committee of University of Cape Coast, Ghana (UCCIRB/CES/2016/04) and the Ghana Health Service Ethics Review Committee (GHS-ERC: 13/12/2016).

\section{REFERENCES}

1. UNICEF. The State of the World's Children, 011: Adolescence an Age of Opportunity. New York, NY: UNICEF (2013).

2. Gouws E, Kruger N, Burger S. The Adolescent. Johannesburg: Heinemann (2008).

3. Shaffer DR, Kipp K. Developmental Psychology: Childhood and Adolescence. Wadsworth: Belmont, CA (2007).

4. World Health Organization. WHO/MPS/09.10. World Health (2009). p 12-8.

5. Stanhope M, Lancaster L, Jessup-Falcioni H, Viverais-Dresler GA. Community Health Nursing in Canada. Toronto: Mosby Elsevier(2008).

6. World Health Organization. WHO Guidelines on Preventing Early Pregnancy and Poor Reproductive Health Outcomes Among Adolescents in Developing Countries. Geneva: WHO (2011).

7. World Health Organization. .Adolescent Pregnancy. Fact sheet No. 364 (2014). Available online at: http://www.who.int/mediacentre/factsheets/fs364/ en/ (accessed October 24, 2014).

8. World Health Organization. Maternal, Newborn, Child and Adolescent Health. Adolescent Pregnancy (2014). Available online at: http://www.who. int/maternal_child_adolescent/topics/maternal/adolescent_pregnancy/en/ (accessed October 24, 2014).

9. United Nations Population Fund. Motherhood in Childhood: Facing the Challenge of Adolescent Pregnancy. New York, NY: UNFPA (2013).

10. Loaiza E, Liang M. Adolescent Pregnancy: A Review of the Evidence. New York, NY: United Nations Population Fund (UNFPA) (2013).

11. Clifton D, Hervish A. The World's Youth 2013 Data Sheet. Washington, DC: Population Reference Bureau (2013).

12. Ghana Statistical Service (GSS) Ghana Health Service (GHS) and ICF Macro (2015). Ghana Health Service (GHS) and ICF Macro. Ghana Demographic and Health Survey 2014, GSS, GHS, and ICF Macro, Accra.

13. KEEA Health Directorate (2016). Annual Health Report. Elmina: KEEA Health Directorate.

14. Ghana Statistical Service (GSS) Ghana Health Service (GHS) and ICF Macro (2003). Ghana Health Service (GHS) and ICF Macro. Ghana Demographic and Health Survey 2003, GSS, GHS, and ICF Macro, Accra.

\section{AUTHOR CONTRIBUTIONS}

BA conceived the study. BA and FS designed and performed the analysis and the write up on data and methods. BA, JH, JM, AAS, and FS designed the first draft of the manuscript. BA, JH, JM, A-AS, FS, TS, and TH revised and proof read the manuscript for intellectual content and gave consent for the final version to be published.

\section{FUNDING}

We acknowledge the support of the School of Graduate Studies, University of Cape Coast, Ghana, and the Neurocognition and Action-Biomechanics Research Group, Bielefeld University, Germany for providing financial support for the conduct of this research.

\section{ACKNOWLEDGMENTS}

We sincerely thank the Health Director of the KEEA Municipality for supporting in the conduct of this research. We also show our gratitude to the staff of the health facilities and respondents for helping with the data collection.

15. Ghana Statistical Service (GSS) Ghana Health Service (GHS) and ICF Macro (2009). Ghana Health Service (GHS) and ICF Macro. Ghana Demographic and Health Survey 2008, GSS, GHS, and ICF Macro, Accra.

16. Imamura $M$, Tucker J, Hannaford $P$, Astin M, Oliveira da Silva M, Bloemenkap KWM, et al. (2006). REPROSTAT 2: A Systematic Review of Factors Associated With Teenage Pregnancy in the European Union. Aberdeen: University of Aberdeen.

17. Goicolea I, Marianne W, Öhman A, San Sebastian M. Risk factors for pregnancy among adolescent girls in Ecuador's Amazon basin: a case-control study. Rev Panamer de Salud Pública. (2009) 26:221-8. doi: 10.1590/S1020-49892009000900006

18. East PL, Reyes BT, Horn EJ. Association between adolescent pregnancy and a family history of teenage births. Perspect Sex Reprod Health. (2007) 39:108-15. doi: 10.1363/3910807

19. Osaikhuwuomwan JA, Osemwenkha AP. Adolescents' perspective regarding adolescent pregnancy, sexuality, and contraception. Asian Pacific J Repr. (2013) 2:58-62. doi: 10.1016/52305-0500(13)60118-9

20. Dulitha F, Nalika G, Manuj W, Upul S. Extent, Trends, and Determinants of Teenage Pregnancy in Three Districts of Sri Lanka. UNFPA (2012).

21. Gyan C. The effects of teenage pregnancy on the educational attainment of girls at Chorkor, a suburb of Accra. J Edu Soc Res. (2013) 3:53-61. doi: 10.5901/jesr.2013.v4n3p53

22. Mushwana L, Monareng L, Richter S, Muller H. Factors influencing the adolescent pregnancy rate in the greater Giyani Municipality, Limpopo Province-South Africa. Int J Africa Nur Sci. (2015) 2:10-8. doi: 10.1016/j.ijans.2015.01.001

23. Cook SMC, Cameron ST. Social issues of teenage pregnancy. Obstetr Gynaecol Repr Med. (2015) 25:9. doi: 10.1016/j.ogrm.2015.06.001

24. Van Rensburg HCJ. In Health and Health Care in South Africa. Pretoria: Van Schaik (2004).

25. Ghana Statistical Service (GSS) (2010). Population and housing census: District analytical report. Accra: Ghana Statistical Service.

26. Krejcie RV, Morgan DW. Determining sample size for research activities. Educ Psychol Meas. (1970) 30:607-10. doi: 10.1177/0013164470030 00308

27. LoBiondo-Wood G, Haber J. Nursing Research: Methods, Critical Appraisal and Utilization. St. Louis: Mosby (2006). 
28. Tabachnick BG, Fidell LS. Using Multivariate Statistics, 5th ed. Boston, MA: Allyn and Bacon (2007).

29. Miller BC, Benson B, Galbraith KA. Family relationships and adolescent pregnancy risk: a research synthesis. Dev Rev. (2001) 21:1-38. doi: 10.1006/drev.2000.0513

30. Miller KS, Forehand R, Kotchick BA. Adolescent sexual behavior in two ethnic minority samples: the role of family variables. J Marriage Fam. (1999) 61:85-98. doi: 10.2307/353885

31. Hogan DP, Kitagawa EM. The impact of social status, family structure, and neighborhood on the fertility of black adolescents. Am J Sociol. (1985) 90:825-55. doi: 10.1086/228146

32. Ku L, Sonenstein FL, Pleck JH. Factors influencing first intercourse for teenage men. Public Health Rep. (1993) 108:680-94.

33. Miller BC, McCoy JK, Olson TD, Wallace CM. Parental discipline and control attempts in relation to adolescent sexual attitudes and behavior. J Marriage Fam. (1986) 48:503-12. doi: 10.2307/352036

34. Resnick MD, Bearman PS, Blum RW, Bauman KE, Harris KM, Jones $\mathrm{J}$, et al. Protecting adolescents from harm: findings from the national longitudinal study on adolescent health. J Am Med Assoc. (1997) 278:823-32. doi: 10.1001/jama.1997.03550100049038

35. East PL. The younger sisters of childbearing adolescents: their attitudes, expectations, and behaviors. Child Dev. (1996) 67:267-82. doi: $10.2307 / 1131813$

36. Jaccard J, Dittus PJ, Gordon VV. Maternal correlates of adolescent sexual and contraceptive behavior. Family Plann Perspect. (1996) 28:159-65. doi: $10.2307 / 2136192$

37. Darling CA, Hicks MW. Parental influences on adolescent sexuality: implication for parents as educators. J Youth Adolesc. (1982) 11:231-45. doi: 10.1007/BF01537469

38. Kahn JR, Smith KW, Roberts EJ. Family Communication and Adolescent Sexual Behavior. Cambridge, MA: Unpublished manuscript, American Institutes for Research (1984).

39. Inazu JK, Fox GL. Maternal influence on the sexual behavior of teenage daughters: direct and indirect sources. J Fam Issues. (1980) 1:81-102. doi: $10.1177 / 0192513$ X8000100105

40. Widmer ED. Influence of older siblings on initiation of sexual intercourse. J Marriage Fam. (1997) 59:928-38. doi: 10.2307/3 53793

41. Jaccard J, Dittus PJ, Litardo HA. Parent-adolescent communication about sex and birth control: implications for parent-based interventions to reduce unintended adolescent pregnancy. In: Severy LJ, Miller WB, Sever L, editors. Advances in Population: Psychological Perspectives, Vol III. London: Jessica Kingsley (1999).

42. Hayes C. Risking the Future: Adolescent Sexuality, Pregnancy and Childbearing. Washington, DC: National Academy Press (1987).

43. Scott-Jones D, White AB. Correlates of sexual activity in early adolescence. J Early Adol. (1990) 10:221-38. doi: 10.1177/02724316901 02008
44. Thobejane TD. Factors contributing to teenage pregnancy in South Africa: the case of matjitjileng village. J Sociol Soc Anthropol. (2015) 6:273-7. doi: 10.1080/09766634.2015.11885667

45. Baker SA, Thalberg SP, Morrison DM. Parents' behavioral norms as predictors of adolescent sexual activity and contraceptive use. Edu Psychol. (1988) 23:265-82.

46. Jaccard J, Dittus P. Parent-Teen Communication: Toward the Prevention of Unintended Pregnancies. New York, NY: Springer-Verlag (1991).

47. Small SA, Luster T. Adolescent sexual activity: An ecological, risk-factor approach. J Marriage Fam. (1994) 56:181-92. doi: 10.2307/352712

48. Weinstein M, Thornton A. Mother-child relations and adolescent sexual attitudes and behaviors. Demography. (1989) 26:563-77. doi: 10.2307/2061258

49. Dittus PJ, Jaccard J, Gordon VV. The impact of African American fathers on adolescent sexual behavior. J Youth Adolesc. (1997) 26:445-65. doi: 10.1023/A:1024533422103

50. Jaccard J, Dittus PJ, Gordon VV. Parent-adolescent congruency in reports of adolescent sexual behavior and in communication about sexual behavior. Child Dev. (1998) 69:247-61. doi: 10.1111/j.1467-8624.1998.tb0 6146.x

51. East PL. Do adolescent pregnancy and childbearing affect younger siblings? Fam Plann Perspect. (1996) 28:148-53. doi: 10.2307/21 36190

52. Haurin RJ, Mott FL. Adolescent sexual activity in the family context: the impact of older siblings. Demography. (1990) 27:537-58. doi: 10.2307/2061569

53. Pick S, Palos PA. Impact of the family on the sex lives of adolescents. Adolescence. (1995) 30:667-75.

54. Ogah JK. Decision Making in the Research Process: Companion to Students and Beginning Researchers. Accra: Adwinsa Publications (Gh) Ltd (2013).

55. Mann CJ. Observational research methods. Research design II: cohort, cross sectional, and case-control studies. Emerg Med J. (2003) 20:54-60. doi: 10.1136/emj.20.1.54

56. Pedrosa AA, Pires $\mathrm{R}$, Carvalho $\mathrm{P}$, Canavarro MC, Dattilio F. Ecological contexts in adolescent pregnancy: the role of individual, sociodemographic, familial, and relational variables in understanding risk of occurrence and adjustment patterns. Contemp Fam Ther. (2011) 33:107. doi: 10.1007/s10591-011-9148-4

Conflict of Interest Statement: The authors declare that the research was conducted in the absence of any commercial or financial relationships that could be construed as a potential conflict of interest.

Copyright (C) 2019 Ahinkorah, Hagan, Seidu, Mintah, Sambah, Schack and Hormenu. This is an open-access article distributed under the terms of the Creative Commons Attribution License (CC BY). The use, distribution or reproduction in other forums is permitted, provided the original author(s) and the copyright owner(s) are credited and that the original publication in this journal is cited, in accordance with accepted academic practice. No use, distribution or reproduction is permitted which does not comply with these terms. 